\title{
Beliefs Toward Social and Cognitive Competences in People with Down Syndrome
}

\author{
Roberto Marcone*, Simona Esposito and Antonietta Caputo
}

Department of Psychology, Second University of Naples, Viale Ellittico, 31, 81100 Caserta, Italy

\begin{abstract}
The inclusion of a person with intellectual disability, such as Down Syndrome (DS), depends not only on the skills of the person himself, but also on the attitude that other persons have to him. Most of the studies that focused on the attitude towards people with DS did not thoroughly investigate the beliefs on the competences of people with DS. Our aim is to identify the commonly held beliefs towards the social and cognitive competences of people with DS. Specifically, we want to verify if there are any differences among the beliefs held by parents of Typical Development (TD) children, parents of people with DS and people without children. A second aim is to evaluate a possible association between the level of knowledge about the Syndrome and related positive beliefs. 363 subjects from 18 to 70 years old $(M=37.56$; S.D. = 14.73) were recruited. The sample was divided in three different groups: 1) subjects with TD children; 2) subjects with DS children and 3) subjects without children. An ad hoc self-report questionnaire was administered. Results show that people with Down Syndrome are considered more competent in terms of motor skills, but less competent in social skills. The level of knowledge of the Syndrome correlates positively with beliefs in all competences. There are differences in beliefs between the three groups: parents with DS children have more positive beliefs about all skills, especially as regards the socialization. Knowing the beliefs on the skills of DS people can be very useful, in order to improve inclusiveness of those with DS.
\end{abstract}

Keywords: Down Syndrome, Intellectual Disabilities, Attitudes and Beliefs, Social Competences, Cognitive Skills, Inclusiveness.

\section{INTRODUCTION}

Down Syndrome is caused by a chromosomal abnormality. It is characterized by mental retardation and specific physical and behavioral traits of the phenotype. These features are easy to recognize; hence, individuals with Down Syndrome (DS) are at risk for being treated as deviant. The attitudes of society can create obstacles for people with Down Syndrome or generally those with intellectual disabilities [1].

It is therefore important to understand the construct of attitude, which consists of cognitive, emotional and behavioral components [2]; in one of the first definitions, it is considered as «an idea charged with emotion which predisposes a class of actions to a particular class of social situations» [3]. The attitude was also defined as «a psychological tendency that is expressed by evaluating a particular entity with some degree of favor or disfavor» [4].

Attitudes regarding intellectual disabilities seem to be affected by many factors such as age, education level and prior contact with a person with intellectual disabilities, while gender difference seems to be not significant [5]. The inclusion of a person with intellectual disability depends not only on the skills of

*Address correspondence to this author at the Department of Psychology, Second University of Naples, Viale Ellittico, 31, 81100 Caserta, Italy; Tel: +39.0823.27.47.85; E-mail: roberto.marcone@unina2.it the person himself, but also on the attitude that other persons have to him $[6,7,8]$. The evaluation of such attitudes appears to be an important index in order to develop both appropriate intervention programs, and focused professional training, as well as, at societal level, to educate and inform the society and the institutions [7]. In simple terms, scholarship could be improved for inclusiveness, too. The studies that have investigated attitudes towards people with Down Syndrome display a divergence of opinions. Some studies show the prevalence of positive attitudes towards the inclusion at work [9] or in the school [10, 11]; others show the prevalence of negative attitudes as concerns those areas [12, 13, 14]. Wishart and Manning [15] found that, although teachers believed there were educational, social and emotional benefits for a child with Down Syndrome in participating in regular classes, they were still reluctant to accept them in their own classes. These opinions may also be affected by inaccurate knowledge about the syndrome and the pessimistic expectations on the developmental outcomes of these children [16]. Negative attitudes were partly related to misconceptions about the abilities of people with intellectual disabilities, such as the belief that these people have serious difficulties, and just few skills [17]. However, other researches highlight how the knowledge of the Syndrome and the proximity to people with Down Syndrome are predictors of a positive attitude and a readiness to work with those with intellectual disabilities [16, 18, 19]. In addition, providing brief information that emphasizes the 
Table 1: Demographic Characteristics of the Sample

\begin{tabular}{|c|c|c|c|c|c|c|c|c|c|c|}
\hline \multirow{2}{*}{ GROUPS } & \multirow{2}{*}{$\mathbf{N}$} & \multicolumn{4}{|c|}{ AGE } & \multicolumn{5}{|c|}{ LSE } \\
\hline & & M & SD & MIN & MAX & $\mathbf{N}$ & M & SD & MIN & MAX \\
\hline W/O & 162 & 23.84 & 5.62 & 18 & 66 & 42 & 1.79 & 1.50 & 1 & 3 \\
\hline$T D$ & 75 & 50.41 & 9.60 & 28 & 70 & 56 & 2.45 & .71 & 1 & 3 \\
\hline$D S$ & 122 & 47.87 & 9.05 & 28 & 67 & 70 & 2.31 & .69 & 1 & 3 \\
\hline TOT & 359 & 37.56 & 14.73 & 18 & 70 & 168 & 2.23 & .79 & 1 & 3 \\
\hline
\end{tabular}

Note: W/O = Without Children; TD = Typical Development; DS = Down Syndrome; LSE = Socio-Economic Level (SES; Hollingshead, 1975) in the Italian validation (LSE; Venuti, Senese, 2007).

capacity of people with intellectual disabilities can lead to a more positive attitude [20]. The attitudes of the community appear to be determinants in supporting people with intellectual disabilities in their itineraries towards social inclusion [16]; indeed, negative attitudes may create obstacles to social inclusion, while positive attitudes may be supportive and have a positive impact on the quality of life of people with Down Syndrome [21]. Therefore, it is important to exactly understand what the attitudes towards people with Down Syndrome are. We must remember, however, that the attitude is a favorable or unfavorable valuation toward something or someone; it is often rooted in beliefs, feelings and exhibited in intentional behavior. Beliefs are ideas about a topic, which sometimes do not refer to a real knowledge of it [22]. Most of the studies focused only on the attitude held towards people with Down Syndrome. However, we think that knowing the beliefs on the skills of people with Down Syndrome can be very useful, in order to change and improve the attitudes of society, and scholarship tout court. Consequently, inclusiveness of those with intellectual disabilities could be improved at different levels, such as at school, at work, yet even at every societal level.

\section{The Aim of the study}

The main aim of this study is to identify the commonly held beliefs towards the social and cognitive competences of people with Down Syndrome. Specifically, the authors want to verify if there are any differences among the beliefs held by parents of Typical Development (TD) children, parents of people with Down Syndrome (DS) and people without children. A second aim is to evaluate a possible association between the level of knowledge about the Syndrome and related positive beliefs. We expected differences in the beliefs among the three groups; in particular, we expected that adults with children with Down Syndrome would highlight more positive beliefs than the other two groups. We also expected that the level of knowledge of the Syndrome would positively affected the beliefs on skills, confirming what has been reported in other studies [16, 18, 19]. In addition, we expected differences among the different areas of expertise investigated.

\section{METHOD}

\section{Participants}

363 subjects ( 241 females), age range from 18 up to 70 years old $(M=37.56$; S.D. $=14.73)$, participated in our study. They were recruited on the basis of their availability, on either the field (in the areas of Caserta, Salerno and Naples, Southern Italy) or online, that allowed us to extend the place of origin of the sample to the whole Country (North: $f=33 ; f \%=9.10$; Centre: $f$ $=24 ; f \%=6.60$; South: $f=295 ; f \%=81.27$; Missing: $f$ $=11 ; f \%=3.03)$. Socioeconomic status of the families was measured with Hollingshead's four-factor index [23], (LSE) [24], considering three levels of estimation ( 1 = Low; 2 = Medium; $3=$ High) the mean level was of 2.23 (S.D = .79; range $=1 \sim 3$ ). The whole sample was divided into three different groups: 1) 75 subjects (20.66\%) with Typical Development (TD) children; 2) 126 subjects (34.71\%) with DS children and 3) 162 subjects $(44.63 \%)$ without children. Demographic descriptions are in Table 1.

\section{Procedure and Materials}

An ad-hoc self-report questionnaire (Down People Competences Questionnaire, DPCQ $)^{1}$ was administered, to be filled in a maximum of 20 minutes, in either paper form or online using Google Modules. The responses to the online questionnaire were given automatically to an Excel file which was then processed by us. Each participant completed the entire questionnaire. The first part of it (37 items) collected data such as gender, age, marital status, educational

\footnotetext{
${ }^{1}$ The Down People Competences Questionnaire (DPCQ) is in Appendix 1.
} 
level, the description of the work and Socio-EconomicStatus [23]. Only for the parents, there was also a part that explored the material/psychological perceived support during pregnancy and after the birth from the partners, grandparents, other relatives and various professionals including Pediatrician and Psychologist. Then, an item investigated if their son/daughter were a Down person, if so, of what kind (Trisomy 21, Translocation, Mosaicism). The second part of the questionnaire (62 items) investigated self-perceived knowledge about the Syndrome (evaluated on five levels: from 1 "I know little or nothing about" to 5 "I have knowledge about it') and the beliefs on the competences of a person with DS. Participants were asked to give their opinion on the statements describing some socio-cognitive skills and the autonomy of the person. For each item they had to indicate on a five-point scale (from -2 "strongly disagree" to +2 "totally agree") if, according to them, a person with Down Syndrome can perform specific activities or if he/she can implement specific skills. The items were grouped into 4 categories: 1) Cognitive and Communicational Competences (items $n=16 ; \alpha=.92$ ); 2) Physical/Motor Skills (items $n=8 ; \alpha=.87$ ); 3) Personal Autonomy (items $n=24$; $\alpha=.95$ ); 4) Social Skills and Rules (items $n=13 ; \alpha=.90$ ). Table 2 shows some examples of items.

\section{Data Analysis}

A first statistical approach was conducted to provide a descriptive analysis of the whole sample. A
Cronbach's Alpha was conducted to evaluate the reliability of the questionnaire. Then, a Chi-Square analysis was conducted to evaluate any differences of perceived support after birth of children between TD and DS parents. Univariate analysis of variance (ANOVA) were conducted to determine if there were differences in beliefs for gender and SES. ANOVA was conducted to determine if there were any differences in beliefs between the three groups (subjects with TD children; subjects with DS children; subjects without children). ANOVA was conducted also to check for any differences in opinion on the various scales (1. Cognitive and Communicational Competences; 2. Physical/Motor Skills; 3. Personal Autonomy; 4. Social Skills and Rules) in each group and in the whole sample. In addition, correlational analysis were conducted to verify a possible association between the level of knowledge of the Syndrome and the beliefs on skills.

\section{RESULTS}

The Chi-Square results underline no significant differences between TD parents and DS parents in the perception of support by Partner $\left(X_{(5)}^{2}=6.517\right.$; n.s. $)$, Maternal grandparents $\left(\chi_{(5)}^{2}=10.429 ;\right.$ n.s. $)$, Other relatives $\left(X_{(5)}^{2}=7.509 ;\right.$ n.s. $)$, Religious associations $\left(X^{2}{ }_{(5)}=5.354 ;\right.$ n.s. $)$, and Gynaecologist's support $\left(X^{2}{ }_{(5)}=\right.$ 9.153; n.s.).

Significant differences were found about Paternal grandparents' support: DS parents perceive less

Table 2: Down People Competences Questionnaire (DPCQ) Sub-Scales, and Sample Items

\begin{tabular}{|c|c|}
\hline DPCQ sub-scales & Sample Items \\
\hline \multirow{3}{*}{ Cognitive and Communicational Competences } & He/She understands what the others say \\
\hline & He/She can complete a puzzle \\
\hline & $\mathrm{He} / \mathrm{She}$ is able to express their needs \\
\hline \multirow{3}{*}{ Physical/Motor Skills } & $\mathrm{He} / \mathrm{She}$ ascends and descends stairs independently \\
\hline & $\mathrm{He} / \mathrm{She}$ is able to ride a bicycle \\
\hline & He/She can play ball \\
\hline \multirow{3}{*}{ Personal Autonomy } & He/She drinks autonomously \\
\hline & $\mathrm{He} / \mathrm{She}$ is able to choose clothes according to climate \\
\hline & He/She can be employed \\
\hline \multirow{3}{*}{ Social Skills and Rules } & $\mathrm{He} / \mathrm{She}$ understands and respects the rules and social norms correctly \\
\hline & He/She participates with competence in the conversation, involving the interlocutors \\
\hline & $\mathrm{He} / \mathrm{She}$ is able to build and maintain an appropriate relationship (friendship, love) \\
\hline
\end{tabular}

Note: The Down People Competences Questionnaire (DPCQ) is in Appendix 1. 
support than TD ones $\left(X_{(5)}^{2}=20.787 ; p<.001\right)$. Contrarily, friends' support - with children $\left(x^{2}(5)=\right.$ 16.016; $p<.05)$ or without children $\left(x_{(5)}^{2}=15.046 ; p<\right.$ $.05)$ - is perceived higher in DS parents than TD ones.

The results about the professional figures underline significant differences, except for the Gynaecologist: the Paediatrist's perceived support seems to be higher in TD parents than DS ones $\left(X_{(5)}^{2}=12.312 ; p<.05\right)$. On the contrary, the Psychologist and Genetist's perceived support seems to be higher in DS' parents than TD's ones (Psychologist: $X_{(5)}^{2}=20.302 ; p<.01$; Genetist: $\left.X^{2}{ }_{(5)}=23.503 ; p<.001\right)$.

The ANOVA showed no significant differences in the beliefs for gender and for Socio-Economic Status (LSE) (see Table 3).

The analysis of variance conducted among the three groups shows significant differences in beliefs in all scales (see Table 4 and Figure 1). The results indicate that the parents of DS children have more positive beliefs than the other two groups. There are also significant differences between the beliefs in the various scales according to the level of knowledge of the Syndrome (see Table 5 and Figure 2). The analysis of variance conducted to test intra-group differences in the beliefs in the various scales shows significant differences in each group. This occurs even if we take into consideration the whole sample. In each group, the beliefs towards the Physical/Motor Skills are more positive than those towards Social Skills and Rules (see Table 6 and Figure 3).

The Pearson's correlational analysis conducted between the level of knowledge of the Syndrome and the beliefs, shows a significant positive correlation for each sub-scales of the Questionnaire: Cog/Comm: $r=$ $.213 ; p<.001 ;$ Motor: $r=252 ; p<.001$; Autonomy: $r=$ 289; $p<.001$; Social: $r=332 ; p<.001$. High levels of knowledge of the Syndrome are significantly and positively associated with the beliefs about all the skills $(r=312 ; p<.001)$.

\section{DISCUSSION}

People with Down Syndrome are considered more competent in terms of motor skills, and less competent in social skills, such as being with others. A wrong conception of intellectual disability could play a role: people may associate intellectual disabilities with deficiencies in social skills tout court, rather than to

Table 3: ANOVA's Results for Gender and Socio-Economic Status (LSE)

\begin{tabular}{|c|c|c|c|c|c|c|}
\hline & \multicolumn{3}{|c|}{ GENDER } & \multicolumn{3}{c|}{ LSE } \\
\hline DPCQ SUBSCALES & $F$ & d.f. & d.f. & F & p \\
\hline \hline Cognitive and Communicational Competence & .142 & 1,358 & n.s. & .554 & 2,165 & n.s. \\
\hline Physical/Motor Skills & .022 & 1,357 & n.s. & .632 & 2,164 & n.s. \\
\hline Personal Autonomy & .053 & 1,358 & n.s. & 2.163 & 2,165 & n.s. \\
\hline Social Skills and Rules & .012 & 1,357 & n.s. & 1,752 & 2,165 & n.s. \\
\hline TOT & .011 & 1,358 & n.s. & 1,373 & 2,165 & n.s. \\
\hline
\end{tabular}

Note: DPCQ = Down People Competences Questionnaire; LSE = Socio-Economic Level (SES; Hollingshead, 1975) in the Italian validation (LSE; Venuti, Senese, 2007).

Table 4: Mean and Standard Deviation of the Beliefs in all DPCQ sub-scales. ANOVA's Results among the Three Groups (Without Children, with Children with Typical Development, and with Children with Down Syndrome)

\begin{tabular}{|c|c|c|c|c|c|c|c|c|c|}
\hline \multirow{2}{*}{ DPCQ SUBSCALES } & \multicolumn{2}{|c|}{$W / 0$} & \multicolumn{2}{|c|}{$T D$} & \multicolumn{2}{|c|}{$D S$} & \multirow{2}{*}{$F$} & \multirow{2}{*}{ d.f. } & \multirow{2}{*}{$p$} \\
\hline & $\mathbf{M}$ & S.D. & $\mathbf{M}$ & S.D. & $\mathbf{M}$ & S.D. & & & \\
\hline $\begin{array}{l}\text { Cognitive and } \\
\text { Communicational } \\
\text { Competence }\end{array}$ & .58 & .61 & .40 & .78 & .86 & .68 & 11.789 & 2,360 & $<.001$ \\
\hline Physical/Motor Skills & .68 & .75 & .78 & .81 & 1.13 & .66 & 13.301 & 2,359 & $<.001$ \\
\hline Personal Autonomy & .50 & .65 & .57 & .75 & .97 & .74 & 16.952 & 2,360 & $<.001$ \\
\hline Social Skills and Rules & .20 & .60 & .15 & .77 & .65 & .70 & 18.937 & 2,359 & $<.001$ \\
\hline TOT & .49 & .55 & .48 & .66 & .90 & .62 & 19.354 & 2,360 & $<.001$ \\
\hline
\end{tabular}

Note: $\mathrm{DPCQ}=$ Down People Competences Questionnaire; $\mathrm{W} / \mathrm{O}=$ Without Children; TD = Typical Development; DS = Down Syndrome. 


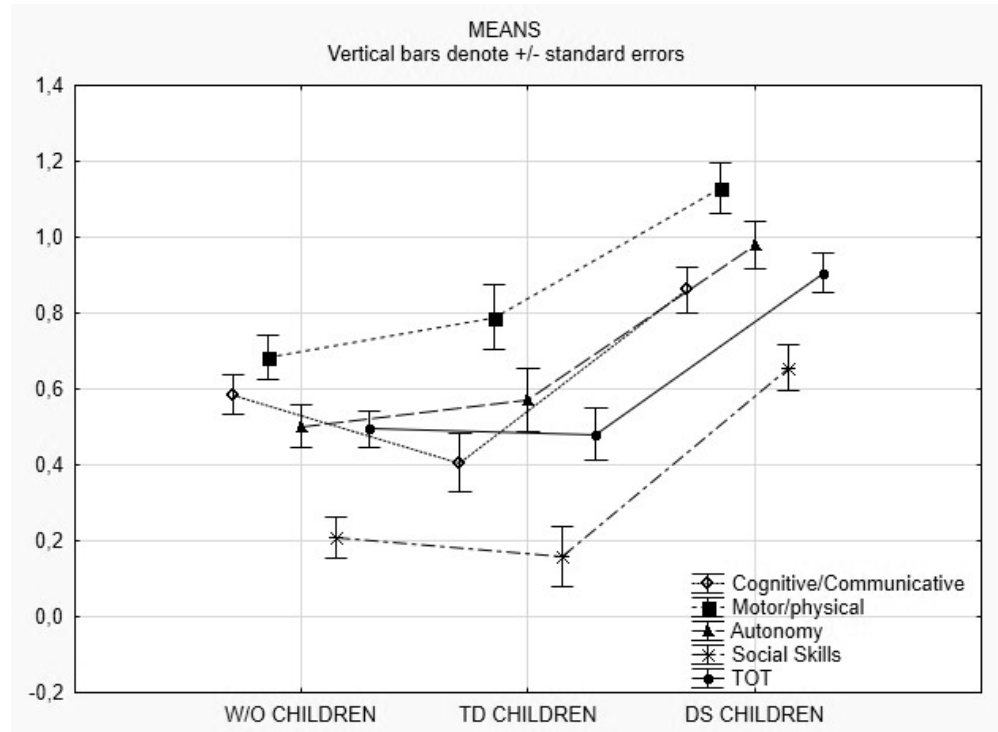

Figure 1: Means and Standard Error of the four sub-scales and total of the Down People Competences Questionnaire (DPCQ) for each sub-sample (Without Children; Typical Development Children; Down Syndrome Children).

Note: $\mathrm{W} / \mathrm{O}=$ Without Children; TD = Typical Development; DS = Down Syndrome.

Table 5: ANOVA's Results among the Five Level of Knowledge about Down Syndrome (from $1=$ low up to $5=$ High) on the Beliefs in all DPCQ Sub-Scales

\begin{tabular}{|c|c|c|c|}
\hline DPCQ SUBSCALES & $\mathbf{F}$ & d.f. & $\mathbf{p}$ \\
\hline Cognitive and Communicational Competence & 4.834 & 4,349 & $<.001$ \\
\hline Physical/Motor Skills & 6.801 & 4,348 & $<.001$ \\
\hline Social Skills and Rules & 11.455 & 4,348 & $<.001$ \\
\hline TOT & 10.701 & 4,349 & $<.001$ \\
\hline
\end{tabular}

Note: DPCQ = Down People Competences Questionnaire.

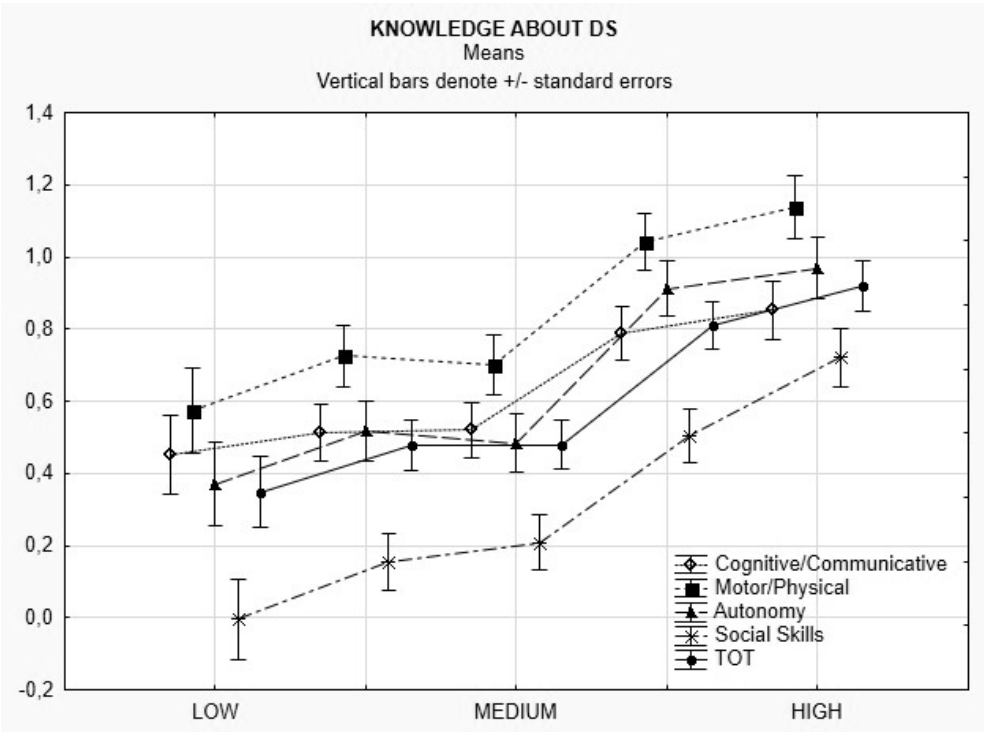

Figure 2: Means and Standard Error of the beliefs towards the skills of people with Down Syndrome (Cognitive and Communicational Competence; Physical/Motor Skills; Personal Autonomy; Social Skills and Rules; and Total) compared to the 5 levels of the Knowledge about the Down Syndrome (from Low = 1 up to High = 5).

Note: Low = Low level (1) of knowledge about DS; Medium = Medium level (3) of knowledge about DS; High = High level (5) of knowledge about DS. 
Table 6: ANOVA's Results among the three Sub-Sample (Without Children, With Children with Typical Development, and With Children with Down Syndrome) and the Total Sample on the four Sub-Scale of the DPCQ and the Total Score

\begin{tabular}{|c|c|c|c|c|c|c|c|c|c|c|c|c|c|}
\hline \multirow{2}{*}{$\begin{array}{l}\text { SUB- } \\
\text { SAMPLE }\end{array}$} & \multicolumn{8}{|c|}{ DPCQ SUBSCALES } & \multicolumn{2}{|c|}{$D P C Q$} & & & \\
\hline & M & S.D. & M & S.D. & M & S.D. & $\mathbf{M}$ & S.D. & $\mathbf{M}$ & S.D. & $F$ & d.f. & $p$ \\
\hline $\begin{array}{l}\text { With TD } \\
\text { Children }\end{array}$ & .40 & .78 & .78 & .81 & .57 & .75 & .16 & .77 & .48 & .66 & 23.099 & 4,296 & $<.001$ \\
\hline $\begin{array}{l}\text { With DS } \\
\text { Children }\end{array}$ & .86 & .68 & 1.12 & .66 & .97 & .74 & .65 & .71 & .90 & .62 & 35.919 & 4,496 & $<.001$ \\
\hline
\end{tabular}

Note: $\mathrm{DPCQ}=$ Down People Competences Questionnaire. $\mathrm{TD}=$ Typical Development. $\mathrm{DS}=$ Down Syndrome.
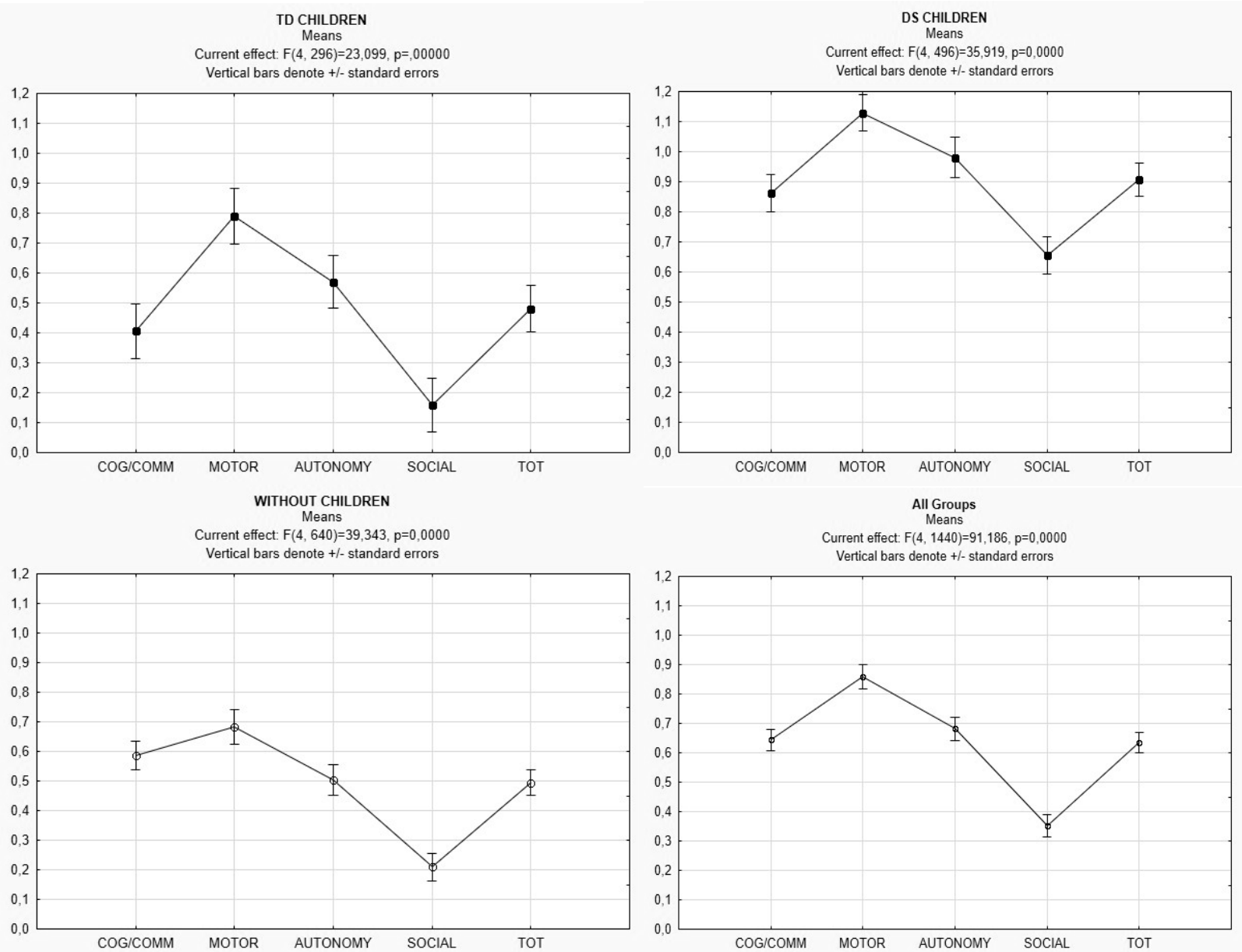

Figure 3: Intra-group ANOVAs among the four sub-scales and total of the Down People Competences Questionnaire (DPCQ).

motor/physical ones. These non-positive beliefs about socialization may influence negatively the inclusiveness of people with Down Syndrome into society. All these beliefs are almost guided by stereotypes (i.e.: " $D S$ people are/are not able to count"; "DS people haven't got friends"), thus neglecting both the considerable 
variation in personality characteristics among individuals, and the variability in mood and behavior within a single individual [16]. Indeed, it is important to take into account that this aspect can play a role in having commonly held expectations about all competences, hence, in inclusiveness tout court.

We found differences in beliefs between the three groups: parents with DS children have more positive beliefs about all skills, especially as regards the socialization. This result could depend on the proximity and the opportunity for parents to observe them better, and it could be the result of a judgment influenced by their expectations or desire to see their children competent. Moreover, those who have a higher knowledge of Syndrome judged the competences of Down people more positively. This may lead us to believe that those who do not have a proper knowledge of the Syndrome do not measure the skills of people with DS appropriately; hence, they could have beliefs that bring them to underestimate the abilities of people with Down Syndrome, perhaps with a tendency to generalize without taking into account the peculiarities of each individual. This aspect is important for inclusiveness tout court, such as education or employment of Down Syndrome people. Moreover, according to several studies [25-27, 29] favourable attitudes towards hiring are associated with previous contact with people with disabilities. The lack of awareness of the potential of a person with intellectual disabilities may lead to damage on his ability to learn and perform a task. According to Werner and Grayzman [19], attitudes and knowledge about disability are factors that predict people's willingness to work with those who have intellectual disabilities. This can be especially essential to understand how to make inclusion both at school and in the workplace even in the whole community. It becomes important to increase the knowledge that people have about Down Syndrome and about the real competences of Down Syndrome people, to understand what roles they can play in society, at school, even in work. To know the real skills of an individual makes it possible to assign him/her tasks that may also be suitable to develop those skills. Indeed, if such skills are never challenged, they can never be implemented. Knowledge and information could help change the stigma around Down Syndrome people. This could have consequences both for the process of inclusiveness, and for an equally important aspect: stigma may become internalized and this can have repercussions for the identity of persons with Down syndrome [30]. This study focused on the beliefs on skills rather than attitudes, and it would be interesting to extend this discussion to intellectual disabilities in general and other diseases associated with them. In addiction, it could be investigate which beliefs on competences are far from the real skills of people with intellectual disabilities. Another important finding may be obtained by administering questionnaires to a sample of operators that have daily contact with people with intellectual disabilities, and by comparing their beliefs with those of the parents.

\section{ACKNOWLEDGEMENTS}

The authors would like to acknowledge the generous support of the AIPD (Associazione Italiana Persone Down - Italian Association of Down People) of Caserta (Italy) (www.aipd.it).

\section{APPENDIX}

\section{Down People Competences Questionnaire}

We ask you to join in a study sponsored by the Department of Psychology of the Second University of Naples, which aims to investigate the social and cognitive skills of people with Down Syndrome and how they are perceived by other actors (parents, adults parents, professionals). A significant amount of research has shown that the quality of life of people with Down Syndrome may be better when the skills of each individual are recognized and promoted, in respect of the general characteristics of the Syndrome itself, and in respect of the individual features. Taking part in the research is voluntary. You will not receive any money, but you will help us grow the knowledge of an important aspect of social and emotional development of people with Down Syndrome.

The collected data will be used exclusively for research purposes and will be subject to confidentiality obligations imposed by the Italian legislation. The data, collected anonymously and marked by an alphanumeric code, will not be subject to communication and dissemination. Moreover, the same data will be used increasingly as a "group" (cohort) and never as an individual. However, by contacting Us, you may oppose the processing of data at any time.

If you want to receive more information about the study, We will be available to provide it. 


\section{REMEMBER}

- $\quad$ Keep the pages in the folder

- $\quad$ Read each question/statement carefully

- $\quad$ Answer every question/statement

- Don't spend a lot of time on each question

- $\quad$ Give the answer that firs counts to you and that seems to make the most sense

- There are no right or wrong answers

- Use a blue or black pen

- Make a marked and clearly visible cross in the spaces

- If you make a mistake completely fill the box and put the cross where it is considered appropriate

\section{Instructions}

Items below are statements on social and cognitive skills and relative autonomy of the person. For each item, you will have to indicate on a five-point scale (from - 2 "strongly disagree" to +2 "totally agree") if, according to them, a person with Down Syndrome can perform the specific activities or can implement specific skills. Remember that there are no right and no wrong answers and that it is important to answer to ALL the items.

\section{SEX M $\quad$ M $F ð$}

AGE

DO YOU OPERATE IN DIAGNOSTIC/REHABILITATION SECTOR?

NO ð YES ठ (if yes, explain)

\section{CHILDREN NO $\quad$ YES $\downarrow$}

\section{CHILDREN WITH DOWN SYNDROME NO ð YES}

Please indicate on a scale from 1 to 5 the degree of knowledge about Down Syndrome

\begin{tabular}{|lllll|}
\hline I know little or nothing & & I have knowledge about it \\
\hline \hline 1 & 2 & 3 & 4 & 5 \\
\hline
\end{tabular}

By answering the following items, please remember to refer to a person with Down Syndrome.

\section{A. Cognitive and Communicational Competences}

\begin{tabular}{|c|c|c|c|c|c|}
\hline A person with Down Syndrome & Very False & Mostly False & $\begin{array}{l}\text { Neither True } \\
\text { nor False }\end{array}$ & Mostly True & Very True \\
\hline 1) He/She understands what the others say & -2 & -1 & 0 & 1 & 2 \\
\hline 3) $\mathrm{He} / \mathrm{She}$ is able to read & -2 & -1 & 0 & 1 & 2 \\
\hline 4) $\mathrm{He} / \mathrm{She}$ is able to write & -2 & -1 & 0 & 1 & 2 \\
\hline 6) He/She is able to complete a puzzle & -2 & -1 & 0 & 1 & 2 \\
\hline 7) He/She manages to build a tower with building blocks & -2 & -1 & 0 & 1 & 2 \\
\hline 8) He/She knows how to draw the human figure & -2 & -1 & 0 & 1 & 2 \\
\hline $\begin{array}{l}\text { 9) In the play he is able to pretend that one object can represent another } \\
\text { (es: bottle = telephone) }\end{array}$ & -2 & -1 & 0 & 1 & 2 \\
\hline
\end{tabular}




\begin{tabular}{|c|c|c|c|c|c|}
\hline 10) $\mathrm{He} / \mathrm{She}$ is able to express their needs & -2 & -1 & 0 & 1 & 2 \\
\hline 11) $\mathrm{He} / \mathrm{She}$ is able to express their thoughts correctly & -2 & -1 & 0 & 1 & 2 \\
\hline 12) $\mathrm{He} / \mathrm{She}$ is able to tell his own day & -2 & -1 & 0 & 1 & 2 \\
\hline 13) He/She is able to understand a newspaper article or a book & -2 & -1 & 0 & 1 & 2 \\
\hline 14) He/She is able to tell what he reads in a newspaper or a book & -2 & -1 & 0 & 1 & 2 \\
\hline 15) He/She is able to recognize and name the seasons & -2 & -1 & 0 & 1 & 2 \\
\hline 16) He/She knows how to orient him/her self in time and space & -2 & -1 & 0 & 1 & 2 \\
\hline
\end{tabular}

\section{B. Physical/Motor Skills}

\begin{tabular}{|c|c|c|c|c|c|}
\hline A person with Down Syndrome & Very False & Mostly False & $\begin{array}{c}\text { Neither True } \\
\text { nor False }\end{array}$ & Mostly True & Very True \\
\hline 1) He/She walks without the assistance of another person & -2 & -1 & 0 & 1 & 2 \\
\hline 3) He/She is able to running, jumping or skipping & -2 & -1 & 0 & 1 & 2 \\
\hline 4) $\mathrm{He} / \mathrm{She}$ is able to drive a nail with a hammer & -2 & -1 & 0 & 1 & 2 \\
\hline 6) $\mathrm{He} / \mathrm{She}$ is able to ride a bicycle & -2 & -1 & 0 & 1 & 2 \\
\hline 7) He/She is able to play ball & -2 & -1 & 0 & 1 & 2 \\
\hline 8) $\mathrm{He} / \mathrm{She}$ is able to dribble the ball with hands & -2 & -1 & 0 & 1 & 2 \\
\hline
\end{tabular}

\section{Personal Autonomy}

\begin{tabular}{|c|c|c|c|c|c|}
\hline A person with Down Syndrome & Very False & Mostly False & $\begin{array}{l}\text { Neither True } \\
\text { nor False }\end{array}$ & Mostly True & Very True \\
\hline 1) He/She eats autonomously & -2 & -1 & 0 & 1 & 2 \\
\hline 2) He/She drinks autonomously & -2 & -1 & 0 & 1 & 2 \\
\hline 3) He/She is able to wash hands and face in autonomy & -2 & -1 & 0 & 1 & 2 \\
\hline 4) He/She knows how to brush his/her teeth & -2 & -1 & 0 & 1 & 2 \\
\hline 5) $\mathrm{He} / \mathrm{She}$ is able to use the toilet autonomously & -2 & -1 & 0 & 1 & 2 \\
\hline 6) He/She knows how to tie his/her shoes & -2 & -1 & 0 & 1 & 2 \\
\hline 7) He/She knows how to dress him/her self & -2 & -1 & 0 & 1 & 2 \\
\hline 8) $\mathrm{He} / \mathrm{She}$ is able to choose clothes according to climate & -2 & -1 & 0 & 1 & 2 \\
\hline 9) He/She is able to take care of their physical appearance & -2 & -1 & 0 & 1 & 2 \\
\hline $\begin{array}{l}\text { 10) If required he/she is able to take the medicine at fixed times (eg: } \\
\text { antibiotics) autonomously }\end{array}$ & -2 & -1 & 0 & 1 & 2 \\
\hline $\begin{array}{l}\text { 11) } \mathrm{He} / \mathrm{She} \text { is able to make small medications (eg: putting a band-aid on } \\
\text { a wound) }\end{array}$ & -2 & -1 & 0 & 1 & 2 \\
\hline 12) $\mathrm{He} / \mathrm{She}$ is able to use cutlery & -2 & -1 & 0 & 1 & 2 \\
\hline 13) $\mathrm{He} / \mathrm{She}$ is able to prepare food & -2 & -1 & 0 & 1 & 2 \\
\hline 14) $\mathrm{He} / \mathrm{She}$ is able to make the bed & -2 & -1 & 0 & 1 & 2 \\
\hline 15) $\mathrm{He} / \mathrm{She}$ is able to tidy his room & -2 & -1 & 0 & 1 & 2 \\
\hline 16) $\mathrm{He} /$ Sheis able to use money and recognizes their value & -2 & -1 & 0 & 1 & 2 \\
\hline 17) $\mathrm{He} / \mathrm{She}$ is able to go out alone & -2 & -1 & 0 & 1 & 2 \\
\hline 18) $\mathrm{He} / \mathrm{She}$ is able to go shopping alone & -2 & -1 & 0 & 1 & 2 \\
\hline 19) He/She is able to set or keep appointments (eg: the dentist) & -2 & -1 & 0 & 1 & 2 \\
\hline
\end{tabular}




20) He/She is able to use the phone to call / answer
21) He/She uses a computer (PC) for simple tasks (word processing,
\begin{tabular}{llll} 
Internet, e-mail ...) & -2 & -1 & 0 \\
\hline 22) He/She can be employed & -2 & -1 & 0 \\
23) He/She is able to organize his/her spare time & -2 & -1 & 0 \\
24) He/She is able to use public transport & -2 & -1 & 0 \\
\hline
\end{tabular}

\section{Social Skills and Rules}

\begin{tabular}{|c|c|c|c|c|c|}
\hline A person with Down Syndrome & Very False & Mostly False & $\begin{array}{l}\text { Neither True } \\
\text { nor False }\end{array}$ & Mostly True & Very True \\
\hline $\begin{array}{l}\text { 1) He/She is able to avoid the manipulation and exploitation of other } \\
\text { people }\end{array}$ & -2 & -1 & 0 & 1 & 2 \\
\hline 2) He/She understands and respects properly the rules and social norms & -2 & -1 & 0 & 1 & 2 \\
\hline 3) He/She knows how to share the play environment & -2 & -1 & 0 & 1 & 2 \\
\hline 6) $\mathrm{He} / \mathrm{She}$ is able to define his/her emotions & -2 & -1 & 0 & 1 & 2 \\
\hline 7) $\mathrm{He} / \mathrm{She}$ is able to help someone in need & -2 & -1 & 0 & 1 & 2 \\
\hline $\begin{array}{l}\text { 8) He/She controls the anger or pain when he is prevented from doing } \\
\text { something }\end{array}$ & -2 & -1 & 0 & 1 & 2 \\
\hline $\begin{array}{l}\text { 11) He/She is able to build and maintain an appropriate relationship } \\
\text { (friendship, love) }\end{array}$ & -2 & -1 & 0 & 1 & 2 \\
\hline 12) $\mathrm{He} / \mathrm{She}$ is able to keep secrets & -2 & -1 & 0 & 1 & 2 \\
\hline 13) $\mathrm{He} / \mathrm{She}$ is able to go on vacation with friends & -2 & -1 & 0 & 1 & 2 \\
\hline
\end{tabular}

Thank you for your precious collaboration.

\section{REFERENCES}

[1] Weisel A, Kravetz S, Shurka-Zernitsky E, Florian V. The structure of attitudes toward persons with disabilities: An Israeli validation of Siller's Disability Factor Scales-General (DFS-G). Rehabilitation Psychology 1988; 33: 227-36.

[2] Olson JM, Zanna MP. Attitudes and attitude change. Annual Review of Psychology 1993; 44: 117-54. http://dx.doi.org/10.1146/annurev.ps.44.020193.001001

[3] Triandis HC. Attitude and attitude change. New York: Wiley; 1971.

[4] Eagly $\mathrm{AH}$, Chaiken S. The psychology of attitudes. Fort Worth: Harcourt Brace Jovanovich 1993.

[5] Katrina S. Public awareness, attitudes and beliefs regarding intellectual disability: A systematic review. Research in Developmental Disabilities 2011; 32: 2164-82. http://dx.doi.org/10.1016/j.ridd.2011.07.005

[6] Abrams D, Wetherell M, Cochrane S, Hogg MA, Turner JC. Knowing what to think by knowing who you are: Selfcategorization and the nature of norm formation, conformity and group polarization. British Journal of Social Psychology 1990; 29(2): 97-119.

http://dx.doi.org/10.1111/j.2044-8309.1990.tb00892.x

[7] Antonak RF, Livneh H. Measurement of Attitudes towards Persons with Disabilities. Disability and Rehabilitation 2000; 22(5): 211-24.

http://dx.doi.org/10.1080/096382800296782
[8] Diamond KE, Kensinger K. Vignettes from Sesame Street: Preschooler's ideas about children with Down syndrome and physical disability. Early Education and Development 2002; 13: 409-21. http://dx.doi.org/10.1207/s15566935eed1304_5

[9] Burge $P$, Ouellette-Kuntz $H$, Lysaght R. Public views on employment of people with intellectual disabilities. Journal of Vocational Rehabilitation 2007; 26: 29-37.

[10] Guralnick MJ, Connor RT, Hammond M. Parent perspectives of peer relationships and friendships in integrated and specialized programs. American Journal of Mental Retardation 1995; 99: 457-76.

[11] Cooney G, Jahoda A, Gumley A, Knott F. Young people with intellectual disabilities attending mainstream and segregated schooling: Perceived stigma, social comparison and future aspirations. Journal of Intellectual Disability Research 2006; 50: $432-44$.

http://dx.doi.org/10.1111/j.1365-2788.2006.00789.x

[12] Siperstein GN, Norris J, Corbin S, Shriver T. Multinational study of attitudes toward individuals with intellectual disabilities: General findings and calls to action. Special Olympics 2003. Available from: http://www. sustainabledesign.ie/arch/2003_Special_Olympicsmultinational_study.pdf.

[13] Burke K, Sutherland C. Attitudes towards inclusion: Knowledge vs. experience. Education 2004; 125: 163-72.

[14] Smith P. Have we made any progress? Including students with intellectual disabilities in regular education classrooms. 
Journal of Intellectual and Developmental Disability 2007; 45: 297-309.

http://dx.doi.org/10.1352/00476765(2007)45[297:HWMAPI]2.0.CO;2

[15] Wishart JG, Manning G. Trainee teachers' attitudes to inclusive education for children with Down's syndrome. Journal of Intellectual Disability Research 1996; 40: 56-65. http://dx.doi.org/10.1111/j.1365-2788.1996.tb00603.x

[16] Gilmore LA, Campbell J, Cuskelly M. Developmental expectations, personality stereotypes, and attitudes towards inclusive education: Community and teacher views of Down syndrome. International Journal of Disability, Development and Education 2003; 50(1): 65-76. http://dx.doi.org/10.1080/1034912032000053340

[17] McCaughey TJ, Strohmer DC. Prototypes as an indirect measure of attitudes toward disability groups. Rehabilitation Counselling Bulletin 2005; 48: 89-99. http://dx.doi.org/10.1177/00343552050480020301

[18] McManus JL, Feyes KJ, Saucier DA. Contact and knowledge as predictors of attitudes toward individuals with intellectual disabilities. Journal of Social and Personal Relationships 2010; 28(5): 579-90. http://dx.doi.org/10.1177/0265407510385494

[19] Werner S, Grayzman A. Factors influencing the intention of students to work with individuals with intellectual disabilities. Research in Developmental Disabilities 2011; 32: 2502-10. http://dx.doi.org/10.1016/j.ridd.2011.07.010

[20] MacDonald JD, Maclntyre PD. A rose is a rose: Effects of label change, education, and sex on attitudes toward mental disabilities. Journal of Developmental Disabilities 1999; 6: 15-31.

[21] Pace JE, Shin M, Rasmussen SA. Understanding attitudes toward people with Down syndrome. American Journal of Medical Genetics 2010; 152(Pt A): 2185-92.
[22]

[23]

Myers DG. Social psychology. New York: McGraw-Hill; 1987.

Hollingshead $A B$. Four factor index of social status (unpublished manuscript). New Haven: Yale University, Department of Sociology 1975.

[24] Venuti P, Senese VP. Un questionario di autovalutazione degli stili parentali: Uno studio su un campione italiano. Giornale Italiano di Psicologia 2007; 3: 677-98. DOI:10.1421/25224

[25] Blessing LA, Jamieson J. Employing persons with developmental disability: effect of previous experience. Canadian Journal of Rehabilitation 1999; 12: 211-21.

[26] Levy JM, Jessop DJ, Rimmerman A, Frencis F, Levy PH. Determinants of attitudes of New York State employers towards the employment of persons with severe handicaps. Journal of Rehabilitation 1993; 59: 49-54.

[27] Morgan RL, Alexander M. The employer's perception: Employment of individuals with developmental disabilities. Journal of Vocational Rehabilitation 2005; 23: 39-49.

[28] Olson D, Cioffi A, Yovanoff P, Mank D. Employers perceptions of employees with mental retardation. Journal of Vocational Rehabilitation 2001; 16: 125-33.

[29] Rimmerman A. Factors Relating to Attitudes of Israeli Corporate Executives Toward the Employability of Persons with Intellectual Disability. Journal of Intellectual and Developmental Disability 1998; 23: 245-55. http://dx.doi.org/10.1080/13668259800033731

[30] Ali A, Hassiotis A, Strydom A, King M. Self stigma in people with intellectual disabilities and courtesy stigma in family carers: A systematic review. Research in developmental disabilities 2012; 33(6): 2122-2140. http://dx.doi.org/10.1016/j.ridd.2012.06.013

\section{DOI: http://dx.doi.org/10.6000/2292-2598.2016.04.01.6}

(c) 2016 Marcone et al.; Licensee Lifescience Global.

This is an open access article licensed under the terms of the Creative Commons Attribution Non-Commercial License (http://creativecommons.org/licenses/by-nc/3.0/) which permits unrestricted, non-commercial use, distribution and reproduction in any medium, provided the work is properly cited. 